\title{
Quality and antioxidant properties of morning bread added with sourdough according to the mixing ratios of sea buckthorn leaf
}

\author{
Min Gyu Park, Hui Yeong Ji, Shin Youn Joo* \\ Department of Food Science and Nutrition, Daejin University, Pocheon 11159, Korea \\ 비타민나무 잎 배합비율에 따른 사워도우 첨가 모닝빵의
품질 특성 및 항산화 활성 \\ 박민규 · 지희영 · 주신윤* \\ 대진대학교 식품영양학과
}

\begin{abstract}
In this study, a natural fermentation starter formulation was developed for functional bread products by substituting baker's yeast with naturally fermented sourdough added with sea buckthom leaf (SBL). The quality and antioxidant properties of morning bread (MB) with $0 \%, 10 \%, 20 \%$, and $30 \%$ SBL added to sourdough were investigated. The pH of MB dough decreased when the mixing ratio (MR) of SBL was increased. The dough-raising power by incubation time (20-60 min) increased when the MR of SBL was increased. In the MB containing 30\% SBL sourdough, the height was lowest, and the baking loss rate was highest. The specific volume of the control was the highest. The $L$ value decreased, whereas the $b$ values increased, when MR of SBL was increased. Hardness was the highest in MB containing 20\% SBL sourdough. Total polyphenolic and total flavonoid contents tended to increase as SBL increased. DPPH and $\mathrm{ABTS}^{+}$radical scavenging activities and reducing power of MB were also elevated due to addition of MR of SBL. The sensory evaluation results revealed that MB containing $20 \%$ SBL sourdough the highest overall preference. Collectively, these results indicated that sourdough with $20 \%$ SBL was a very useful substitute for baker's yeast when making naturally fermented functional bread.
\end{abstract}

Key words : sea buckthom leaf, sourdough, moming bread, quality characteristics, antioxidant activity

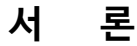

최근 산업 발달과 1 인 가구, 핵가족화, 맞벌이 및 고령 가 구 등으로 인한 생활양식의 변화는 가공식품, 간편식, 고지방 동물성식품 섭취 증가의 원인이다. 생활양식의 변화는 1 인당 쌀 소비량의 감소로 이어졌으며, 쌀 대체 식품으로 빵류의 소 비량은 꾸준하게 증가하였는데, 이는 소비자들이 식료품 소비 에 사용하는 지출비 중에서 빵류에 대한 지출액이 증가한 것
을 뒷받침한다. 이러한 생활양식은 비만, 생활습관병 등의 질 병증가로 연결되어 사회적인 문제가 되고 있다(Choi와 Cho, 2018; Park 등, 2018). 소비자들의 건강에 대한 관심이 높아 지면서 건강한 라이프 스타일을 영위하고자 생리활성이 우수 한 소재가 첨가된 건강 기능성 식품의 수요가 증가하였고, 제 과제빵 산업에서도 빵에 기능성 성분이 함유된 곡물이나 부 재료를 첨가하여 기능성을 증대시키는 것을 중요하게 생각하 고 있다(Angioloni와 Collar, 2011; Moon 등, 2004). 기능성

*Corresponding author. E-mail : joo@daejin.ac.kr, Phone : +82-31-539-1865, Fax : +82-31-539-1860

Received 06 May 2021; Revised 30 June 2021; Accepted 01 July 2021.

Copyright (c) The Korean Society of Food Preservation.

This is an Open Access article distributed under the terms of the Creative Commons Attribution Non-Commercial License (http://creativecommons.org/licenses/by-nc/4.0) which permits unrestricted non-commercial use, distribution, and reproduction in any medium, provided the original work is properly cited. 
부재료를 첨가한 제빵 연구로는 마른 김 첨가 모닝빵(Baek 등, 2018), 비타민나무 열매가루 첨가 식방(Lee와 Kim, 2020), 발아 카무트 분말 첨가 식빵(Yoon 등, 2020) 등 다양한 연구 가 진행되고 있다.

사워도우는 B.C. 2000 년경 이집트에서 유래된 밀 또는 호 밀 가루를 물과 함께 혼합해서 발효시킨 신맛이 나는 천연 발효 반죽으로 중세시대에 유럽으로 전해졌다(Capelle 등, 2013). 사워도우는 제빵에 이용되는 천연물로 발효 과정에서 야생효모와 유산균에 의해 밀이나 호밀 가루의 탄수화물이 분해되고, 부산물로 lactic acid, acetic acid, ethanol 및 $\mathrm{CO}_{2}$ 가 형성되어 일반적으로 이스트를 사용한 빵과는 다르게 특 유의 풍미가 있다(Kulp와 Lorenz, 2003). 사워도우는 완성된 빵의 풍미를 향상시키는 것 외에도 반죽의 물성 개량, 곰팡이 생육 저해 및 수분 보유력이 높아 빵의 노화를 지연시키므로 저장성을 향상시키는 장점이 있다. 또한 미네랄의 흡수를 증 진시키고 혈당지수를 감소시키는 효과가 있다(Sakandar 등, 2019; Siepmann 등, 2018). 최근 소비자들에게 사워도우의 장점과 건강에 대한 기능성이 알려지면서 관심이 증가하고 있다. 사워도우의 품질에 중요한 영향을 미치는 요인으로는 첨가되는 재료와 환경 및 종균 배양이 있으며, 완성된 사워도 우 빵의 가공 적성과 맛 그리고 영양적 가치는 첨가되는 재료 에 의해 개선이 가능하다(Sanz-Penella 등, 2012). 최근 사워 도우 가공 적성에 대한 연구로는 홍국(Lee 등, 2007), 건포도 천연 발효액(Kim과 Chun, 2009), 블루베리 천연 발효액종 (Choi, 2013), 막걸리(Yoo 등, 2017) 등이 있으며, 기능성에 대한 연구로는 아로니아 sourdough starter(Sim 등, 2019), 사 워도우와 퀴노아 분말(Jung 등, 2020) 등이 있다. 하지만 사 워도우의 가공 적성에 대한 연구는 그 수가 적고 기능성에 대한 연구는 매우 부족하며, 비타민나무 잎을 이용한 사워도 우 연구는 전무한 실정이다.

비타민나무(Sea buckthorn, Hippophae rhamnoides)는 보 리수나무과의 낙엽활엽 관목으로 병충해가 적고 내한성이 우 수하여 재배 및 관리가 용이한 식물로, 현재 우리나라에서도 강원(철원, 화천, 춘천) 및 경기(포천) 지역에서 재배하고 있 다. 비타민나무는 갈매보리수나무, 산자나무 등 다양한 이름 으로 불린다(Guan 등, 2005; Kim 등, 2009; Park 등, 2010). 비타민나무는 식물의 부위(잎이나 열매, 종자 및 뿌리 등)와 상관없이 건강에 유익한 영양성분 및 기능성 물질이 다량 함 유되어 있어 항산화, 항당뇨 및 항균 등 생리활성이 높은 식 물이다(Kallio 등, 2002). 특히 비타민나무 잎은 polyphenol, flavonoid, carotenoid 및 ascorbic acid의 함량이 높아 항산화 활성이 뛰어난 기능성 식품으로 일부 국가에서 이용 중이다. 우리나라에서 재배되는 비타민나무 잎이 몽골에서 재배되는 것보다 polyphenol 함량이 5 배나 더 높다고 보고되었다(Pang
등, 2008)

따라서 본 연구에서는 비타민나무 잎의 배합비율을 달리 한 사워도우를 제조하여 모닝빵 제조 시 이스트의 일부를 대 체한 발효제로 첨가하였다. 또한 비타민나무 잎 사워도우를 첨가한 모닝빵의 품질 특성 및 항산화 활성을 측정하여 비타 민나무 잎 사워도우를 이용한 기능성 모닝방을 개발하고, 더 나아가 제빵산업의 활성화에 기여하고자 하였다.

\section{재료 및 방법}

\section{실험재료}

본 실험에 사용된 재료는 비타민나무 잎 분말(Samsung Herb Medicine Agricutural Co., Chuncheon, Korea), 건포도 (Wooriga. Inc., Yangju. Korea), 강력 밀가루(CJ Cheiljedang Co., Yangsan, Korea), 설탕(CJ Cheiljedang Co., Incheon, Korea), 전지분유(Seoulmilk, Yangju, Korea), 소금(Korea salt manufacture association, Mokpo, Korea), 버터(Lotte Food Co., Cheonan, Korea), 드라이이스트(Saf-instant, Lesaffre, Lille, France), 달걀은 모두 시중에서 구입하였다.

\section{액종 및 sourdough 분말 제조}

액종 제조는 건포도를 $30^{\circ} \mathrm{C}$ 물로 가볍게 헹군 뒤 살균된 유 리병에 건포도와 물을 $1: 3$ 비율로 넣었다. 건포도와 물 혼합물 총 중량의 $3.5 \%$ 의 설탕을 첨가하여 뚜껑을 닫고 충분히 교반 한 후 $26^{\circ} \mathrm{C}$ 로 고정된 incubator(C-SKI-1, Changshin Scientific Co., Seoul, Korea)에서 24시간 1차 발효시켰다. 산소공급을 위하여 24시간마다 뚜껑을 여닫은 후 충분히 교반하여 72 시 간 2차 발효시켰다. 발효가 끝난 액종은 60 mesh sieve(Chung Gye Industrial Mfg., Co., Seoul, Korea)로 걸러 완성하였다.

Sourdough는 완성된 액종과 밀가루를 1:1 비율로 살균된 유리병에 넣고 밀가루 중량의 $1 \%$ 소금을 첨가하여 고무주걱 으로 균일하게 섞은 뒤 $26^{\circ} \mathrm{C}$ incubator에서 24시간 1 차 발효 시켰다. Sourdough의 2 차 발효와 3 차 발효는 1 차 발효와 동 일한 조건으로 진행하였다. 완성된 sourdough는 상온에서 24 시간 건조시킨 뒤 분쇄하여 35 mesh sieve(Chung Gye Industrial Mfg., Co., Seoul, Korea)에 내린 후 초저온 냉동고 (DF9010, Ilshin Bio Base, Gyeonggi-do, Korea)에 보관하면 서 사용하였다.

\section{비타민나무 잎 첨가 sourdough 제조}

분말화한 sourdough, 밀가루 및 물을 7:15:22 비율로 살균 된 유리병에 넣은 후 총 중량의 $1 \%$ 소금을 첨가하여 고무주 걱으로 균일하게 섞은 뒤 incubator $\left(26^{\circ} \mathrm{C}, 24\right.$ 시간)에서 1 차 발효를 진행하여 sourdough를 활성화시켰다. 1차 발효가 끝 
난 sourdough에 밀가루와 물을 1:1:1 비율로 넣은 후 밀가루 와 물을 합친 중량의 $1 \%$ 소금을 첨가하여 고무주걱으로 균 일하게 섞은 뒤 incubator( $26^{\circ} \mathrm{C}, 24$ 시간)에서 2차 발효시켰다. 3 차 발효는 2차 발효와 동일한 조건으로 진행하여 sourdough 를 제조하였다. 3 차 발효가 끝난 sourdough와 밀가루(밀가루 대비 $0 \%, 10 \%, 20 \%, 30 \%$ 의 비타민나무 잎 첨가), 물을 $1: 2: 2$ 비율로 살균된 유리병에 넣은 후 총 중량의 $1 \%$ 소금을 첨가하여 고무주걱으로 균일하게 섞은 뒤 incubator $\left(26^{\circ} \mathrm{C}\right)$ 에 서 부피가 2 배가 될 때까지 발효시켜 비타민나무 잎 첨가 sourdough starter를 제조하였다.

\section{모닝빵 제조}

모닝빵을 제조하기 위한 재료와 분량은 다음과 같다. 밀가 루 $300 \mathrm{~g}$, 사워도우 $120 \mathrm{~g}$, 물 $90 \mathrm{~g}$, 설탕 $45 \mathrm{~g}$, 분유 $9 \mathrm{~g}$, 소금 $5.5 \mathrm{~g}$, 버터 $30 \mathrm{~g}$, 이스트 $4.5 \mathrm{~g}$, 달걀 $60 \mathrm{~g}$ 을 이용하여 제조하 였다. 버터를 제외한 모든 재료를 반죽기 $(5 \mathrm{~K} 5 \mathrm{SS}$, Kitchenaid, Joseph, MI, USA)에 넣고 저속으로 3분간 클린업 상태가 되 도록 반죽한 다음 버터를 넣고 저속에서 6 분간 반죽하였다. 볼에 반죽을 넣고 발효기(EP-20, Daeyoung Co., Daejeon, Korea)에서 1 차 발효 $\left(30^{\circ} \mathrm{C}\right.$, 습도 $80 \%, 90$ 분)를 진행하였다. 1 차 발효가 끝난 반죽은 $30 \mathrm{~g}$ 씩 분할하여 동그란 모양으로 성형 후 실온에서 30 분간 벤치타임을 주었다. 2 차 발효는 1 차 발효와 동일한 조건으로 진행하였다. 발효가 끝난 반죽은 윗불 $190^{\circ} \mathrm{C}$, 아랫불 $150^{\circ} \mathrm{C}$ 로 예열된 오븐(FDO-7102, Daeyoung, Daejeon, Korea)에서 8분 동안 굽고, 완성된 모닝빵은 실온 에서 1 시간 방냉한 후 폴리에틸렌 비닐로 포장하여 시료로 사용하였다.

\section{모닝빵 반죽의 $\mathrm{pH}$ 및 발효팽창력 측정}

모닝빵 반죽의 $\mathrm{pH}$ 는 반죽 $3 \mathrm{~g}$ 에 증류수 $27 \mathrm{~mL}$ 를 넣고 1 분간 균질기(Omni $\mu \mathrm{H}$ Homogenizer, Omni International, GA, USA)로 균질화한 후 여과지(Whatman NO. 1, Whatman International Ltd, Maidstone, UK)로 여과하여 $\mathrm{pH}$ meter (Orion star A211, Thermo Fisher Scientific Inc., Waltham, $\mathrm{MA}, \mathrm{USA}$ )로 측정하였다.

발효팽창력은 $50 \mathrm{~mL}$ conical tube에 모닝빵 반죽 $10 \mathrm{~g}$ 을 넣고 표면이 고르고 판판하게 한 후, 20 분 간격으로 120 분간 발효(온도 $30^{\circ} \mathrm{C}$, 습도 $80 \%$ )시키면서 측정하였다. 이때 모든 시료는 동일한 부피 $(9 \mathrm{~mL})$ 에서 발효를 시작하였고, 20 분 간 격으로 반죽이 팽창하여 올라온 가장 높은 부분의 눈금을 측 정하였다(Lee, 2015).

\section{모닝빵의 높이, 굽기손실률, 비용적 및 수분함량 측정}

모닝빵의 높이는 빵을 반으로 자른 후 잘린 단면의 가장
높은 부분을 자로 측정하였다. 굽기 손실률은 굽기 전·후의 중량을 각각 측정 후 그 차이에 대한 비율로 산출하였다. 비 용적은 모닝빵의 중량에 대한 부피의 비 $(\mathrm{mL} / \mathrm{g})$ 로 산출하였 다. 수분함량은 시료 일정량 $(0.5 \mathrm{~g}$ 내외 $)$ 을 칭량한 후 적외선 수분 측정기(MB- 45 , Ohaus, NJ, USA)로 $105^{\circ} \mathrm{C}, 10$ 분간 측 정하였다.

\section{모닝빵 색도 측정}

모닝빵의 색도는 모닝빵을 일정한 크기(가로 $2.5 \mathrm{~cm} \times$ 세로 $2.5 \mathrm{~cm} \times$ 높이 $2.5 \mathrm{~cm})$ 로 잘라 내부 표면을 색차계 $(\mathrm{JX} 777$, Juki, Tokyo, Japan)를 이용하여 L값(lightness), a값(redness), $\mathrm{b}$ 값(yellowness)을 측정하였다. 표준 백색판의 $\mathrm{L}$ 값, $\mathrm{a}$ 값, $\mathrm{b}$ 값 은 각각 $98.50,0.09,-0.46$ 이었다.

\section{모닝빵 조직감 측정}

모닝빵의 조직감은 texture analyzer(TAXT Plus, Stable Micro System Ltd., Surrey, UK)를 이용하여 TPA(texture profile analysis) test를 측정하였으며, probe는 $35 \mathrm{~mm}$ cylinder probe를 사용하여 연속적으로 2회 눌렀을 때 얻어지 는 힘-시간 곡선으로부터 산출된 값으로 경도(hardness), 탄 력성(springiness), 응집성(cohesiveness), 씹힘성(chewiness) 및 검성(gumminess)을 측정하였다. 분석조건은 pre-test speed $1.0 \mathrm{~mm} / \mathrm{sec}$, test speed $1.0 \mathrm{~mm} / \mathrm{sec}$, post-test speed 5.0 $\mathrm{mm} / \mathrm{sec}$, test distance $14.0 \mathrm{~mm} / \mathrm{sec}$, trigger force $5.0 \mathrm{~g}$ 으로 하였다. 이때 시료는 일정한 크기 $(2.5 \times 2.5 \times 2.5 \mathrm{~cm})$ 로 잘라서 사용하였다.

\section{모닝빵의 총페놀 및 총플라보노이드 함량 측정}

모닝빵 $20 \mathrm{~g}$ 에 $80 \%$ 에탄올 $100 \mathrm{~mL}$ 를 넣고 $20^{\circ} \mathrm{C}$ shaking incubator(SI-900R, JeioTech, Daejeon, Korea)에서 24시간 추출하여 추출액을 얻었다. 추출액은 여과지로 여과 후 시료 액으로 사용하였다.

총페놀 함량은 Lin과 $\operatorname{Tang}(2007)$ 의 방법을 응용하여 측정 하였다. 모닝빵 추출물 $100 \mu \mathrm{L}$ 에 Folin-Ciocalteu reagent $200 \mu \mathrm{L}$ 와 증류수 $2 \mathrm{~mL}$ 를 혼합하여 3분간 방치하고, 이 반응 액에 $10 \% \mathrm{Na}_{2} \mathrm{CO}_{3} 2 \mathrm{~mL}$ 를 넣고 암소에서 60 분 동안 반응시 킨 후 $765 \mathrm{~nm}$ 에서 분광광도계(EMC-18PC-UV, EMCLAB $\mathrm{GmbH}$, Duisburg, Germany)로 흡광도를 측정하였다. 표준 곡선은 농도별로 반응시킨 gallic acid 값으로 나타냈으며, 모 닝빵 $100 \mathrm{~g}$ 당 $\mathrm{mg}$ gallic acid equivalent(mg GAE/100 g)로 결과를 나타냈다.

총플라보노이드 함량은 Lee 등(1997)의 방법을 응용하여 측정하였다. 시료 용액 $100 \mu \mathrm{L}$ 에 $1 \mathrm{~N} \mathrm{NaOH} 300 \mu \mathrm{L}$ 와 diethylenglycol $2 \mathrm{~mL}$ 를 혼합하여 $37^{\circ} \mathrm{C}$ 에서 1시간 반응시킨 
후 $420 \mathrm{~nm}$ 에서 흡광도를 측정하였다. 표준 곡선은 농도별로 반응시킨 naringin 값으로 나타냈으며, 모닝빵 $100 \mathrm{~g}$ 당 $\mathrm{mg}$ naringin equivalent $(\mathrm{mg} \mathrm{NE} / 100 \mathrm{~g})$ 로 결과를 나타냈다.

\section{모닝빵의 DPPH 라디칼 소거능 측정}

$\mathrm{DPPH}$ 라디칼 소거능은 Lee 등(2007)의 방법을 응용하여 측정하였다. 시료 용액은 총페놀 및 총플라보노이드 함량에 서 제조한 방법과 동일한 방법을 사용하였으며, 시료 농도는 $50 \mathrm{mg} / \mathrm{mL}$ 로 희석하여 사용하였다. 시료 용액 $500 \mu \mathrm{L}$ 에 $\mathrm{DPPH}$ 용액 $\left(1.5 \times 10^{-4} \mathrm{M}\right) 2 \mathrm{~mL}$ 를 가하고, 30 분간 암소에서 반응시킨 후 $517 \mathrm{~nm}$ 에서 흡광도를 측정하였다. $\mathrm{DPPH}$ 라디 칼 소거능은 아래의 식으로 계산하여 나타내었다.

DPPH radical scavenging activity $(\%)=$

$$
[1-(\mathrm{A} / \mathrm{B})] \times 100
$$

A: absorbance value of sample

B: absorbance value of control

\section{모닝빵의 $\mathrm{ABTS}^{+}$라디칼 소거능 측정}

$\mathrm{ABTS}^{+}$라디칼 소거능은 $\mathrm{Re}$ 등(1999)의 방법에 응용하여 측정하였다. 시료 용액은 총페놀 및 총플라보노이드 함량에 서 제조한 방법과 동일한 방법을 사용하였으며, 시료 농도는 $50 \mathrm{mg} / \mathrm{mL}$ 로 희석하여 사용하였다. $7 \mathrm{mM} \mathrm{ABTS}$ 와 2.45 $\mathrm{mM}$ potassium persulfate를 14:1 비율로 혼합 후 암소에서 20시간 반응시켜 ABTS solution을 제조하였다. 반응이 끝난 ABTS solution은 $734 \mathrm{~nm}$ 에서 흡광도 값이 $0.70 \pm 0.02$ 가 되 도록 증류수로 희석하여 실험에 사용하였다. 시료 용액 100 $\mu \mathrm{L}$ 에 $\mathrm{ABTS}$ 용액 $1.6 \mathrm{~mL}$ 를 넣고 5 분 동안 반응시킨 후 734 $\mathrm{nm}$ 에서 흡광도를 측정하였다. $\mathrm{ABTS}^{+}$라디칼 소거능은 아래 의 식으로 계산하여 나타내었다.

$\mathrm{ABTS}^{+}$radical scavenging activity $(\%)=$

$$
[1-(\mathrm{A} / \mathrm{B})] \times 100
$$

A: absorbance value of sample

B: absorbance value of control

\section{모닝빵의 환원력 측정}

환원력은 Wong과 Chye(2009)의 방법을 응용하여 측정하 였다. 시료 용액은 총페놀 및 총플라보노이드 함량에서 제조한 방법과 동일한 방법을 사용하였으며, 시료 농도는 $200 \mathrm{mg} / \mathrm{mL}$ 로 희석하여 사용하였다. 시료 용액 $500 \mu \mathrm{L}$ 에 $0.2 \mathrm{M}$ phosphate buffer $0.5 \mathrm{~mL}(\mathrm{pH}$ 6.6)와 $1 \%$ potassiumferricyanide $500 \mu \mathrm{L}$ 를 혼합하여 $50^{\circ} \mathrm{C}$ 에서 20 분 반응시켰다. 이 반응액에 $10 \% \mathrm{TCA}$ (trichloroacetic acid) 용액 $500 \mu \mathrm{L}$ 를 가하고 혼합
한 뒤 10 분간 원심분리(CF-10, Daihan Scientific Co., Wonju, Korea)하여 상층액 $1 \mathrm{~mL}$ 를 취하였다. 여기에 증류수 $1 \mathrm{~mL}$ 를 가한 뒤 $0.1 \% \mathrm{FeCl}_{3} 200 \mu \mathrm{L}$ 를 혼합하여 $700 \mathrm{~nm}$ 에서 흡 광도를 측정하였다.

\section{관능검사}

비타민나무 잎 sourdough 첨가 모닝빵의 관능검사는 소비 자 기호도로 평가하였다(대진대학교 생명윤리심의위원회 승 인번호: 1040656-202104-HR-01-03). 연령대(20-30대)가 비슷 한 교직원 및 대학원생 15 명을 선정하여 관능평가를 시행하 기 전에 실험의 목적 및 취지를 충분히 설명하고, 평가방법을 교육시킨 후 관능검사에 응하도록 하였다. 모닝빵은 정중앙을 중심으로 반으로 잘라 난수표를 이용하여 세 자리 숫자를 부 착한 흰색 폴리에틸렌 1 회용 접시에 내부의 색이 보이도록 담 아 동시에 제공하였고, 7점 척도법(1점: 대단히 많이 싫어한 다, 7점: 대단히 많이 좋아한다)을 이용하여 소비자 기호도에 대하여 평가하도록 하였다. 소비자 기호도 평가항목은 전반적 인 기호도, 외관, 색, 향미, 맛 및 조직감에 대하여 실시하였다. 이때 다른 시료 평가에 미치는 영향을 줄이고자 미지근한 물 을 제공하여 한 개의 시료를 섭취한 후 입안을 미지근한 물로 충분하게 헹군 후 다른 시료를 평가하도록 하였다.

\section{통계처리}

본 연구의 결과는 3 회 이상의 반복 실험으로 얻은 값을 SPSS statistics(ver. 26, IBM Co., Armonk, NY, USA) 통계 프로그램을 통해 분산분석(ANOVA)으로 각 시료 간 유의성 검증을 하였으며, 평균 \pm 표준편차로 나타내었다. 유의성이 있 는 경우에는 사후검증으로 Duncan's multiple range test를 실시하였다 $(\mathrm{p}<0.05)$.

\section{결과 및 고찰}

\section{모닝빵 반죽의 $\mathrm{pH}$ 및 발효팽창력}

비타민나무 잎 배합비율에 따른 사워도우 첨가 모닝빵 반 죽의 $\mathrm{pH}$ 및 발효팽창력 측정 결과는 Table 1 과 같다. 일반적 으로 반죽의 $\mathrm{pH}$ 는 제빵에서 완성된 빵의 조직감과 부피에 큰 영향을 미치고 빵의 가스 보유력 및 발효를 결정하는 요인이 다(Lee 등, 2003). 반죽의 $\mathrm{pH}$ 는 대조군이 5.55, 비타민나무 잎 사워도우 $10-30 \%$ 첨가군이 5.27-5.45로 비타민나무 잎 배 합비율이 증가할수록 유의적으로 감소하였다 $(\mathrm{p}<0.05)$. 사워 도우와 퀴노아 분말 첨가 모닝방 연구(Jung 등, 2020)에서도 시료 첨가량이 증가할수록 $\mathrm{pH}$ 가 감소하는 경향을 보여 본 실 험 결과와 유사하였다. Tae 등(2015)은 빵 반죽의 $\mathrm{pH}$ 는 첨가 되는 재료의 $\mathrm{pH}$ 및 삼투압 등에 영향을 받는다고 보고하였는 
Table 1. pH and dough raising power of moming bread dough added with sourdough starter according to the mixing ratio of sea buckthom leaf

\begin{tabular}{cccccc}
\hline & & Control $^{1)}$ & SBLS 10 & SBLS 20 & SBLS 30 \\
\hline & & $5.55 \pm 0.01^{2) \mathrm{a} 3)}$ & $5.45 \pm 0.02^{\mathrm{b}}$ & $5.38 \pm 0.03^{\mathrm{c}}$ & $5.27 \pm 0.01^{\mathrm{d}}$ \\
\hline & $20 \mathrm{~min}$ & $9.00 \pm 0.00^{\mathrm{bF} 4)}$ & $9.50 \pm 0.00^{\mathrm{bD}}$ & $9.33 \pm 0.29^{\mathrm{bF}}$ & $10.67 \pm 0.58^{\mathrm{aD}}$ \\
& $40 \mathrm{~min}$ & $11.00 \pm 0.00^{\mathrm{bE}}$ & $10.83 \pm 0.29^{\mathrm{bD}}$ & $10.83 \pm 0.29^{\mathrm{bE}}$ & $14.00 \pm 1.32^{\mathrm{aCD}}$ \\
$\begin{array}{c}\text { Dough raising } \\
\text { power }\end{array}$ & $60 \mathrm{~min}$ & $14.00 \pm 0.00^{\mathrm{bD}}$ & $14.83 \pm 1.04^{\mathrm{bC}}$ & $14.17 \pm 0.29^{\mathrm{bD}}$ & $17.83 \pm 2.02^{\mathrm{aBC}}$ \\
& $80 \mathrm{~min}$ & $17.50 \pm 0.00^{\mathrm{ns} 5) \mathrm{C}}$ & $18.33 \pm 1.44^{\mathrm{BC}}$ & $17.00 \pm 0.87^{\mathrm{C}}$ & $20.67 \pm 2.52^{\mathrm{B}}$ \\
& $100 \mathrm{~min}$ & $21.00 \pm 0.00^{\mathrm{nsB}}$ & $22.17 \pm 2.93^{\mathrm{B}}$ & $20.83 \pm 0.29^{\mathrm{B}}$ & $25.00 \pm 2.50^{\mathrm{A}}$ \\
& $120 \mathrm{~min}$ & $24.67 \pm 0.29^{\mathrm{nsA}}$ & $26.17 \pm 4.25^{\mathrm{A}}$ & $23.00 \pm 0.00^{\mathrm{A}}$ & $27.33 \pm 3.25^{\mathrm{A}}$ \\
\hline
\end{tabular}

${ }^{1)}$ Control, sourdough starter without sea buckthorn leaf; SBLS 10, 10\% sea buckthorn leaf sourdough starter; SBLS 20, 20\% sea buckthorn leaf sourdough starter; SBLS 30, 30\% sea buckthorn leaf sourdough starter; SBLS, sea buckthorn leaf sourdough starter.

${ }^{2}$ Result are mean values \pm SD $(n=3)$.

3)a-d Means with different lowercase letters in the same row are significantly different by Duncan's multiple range test at $\mathrm{p}<0.05$.

${ }^{4) A-F}$ Means with different uppercase letters in the same column are significantly different by Duncan's multiple range test at $\mathrm{p}<0.05$.

${ }^{5)}$ ns, not significant.

데, 비타민나무 잎은 acetic $\operatorname{acid}(6.19 \mathrm{mg} / \mathrm{g}), \operatorname{lactic} \operatorname{acid}(6.50$ $\mathrm{mg} / \mathrm{g})$, malic $\operatorname{acid}(2.83 \mathrm{mg} / \mathrm{g})$ 등의 유기산이 함유되어 있어 비타민나무 잎 배합비율이 증가할수록 $\mathrm{pH}$ 가 감소한 것으로 사료된다(Lee 등, 2018). 또한 $\mathrm{Kim}$ 등(2011)의 보고에 따르 면 가스 보유력은 $\mathrm{pH}$ 5.0-5.5 범위에서 가장 우수하며, 이스 트 활성은 $\mathrm{pH}$ 4.7에서 최대가 된다고 하여 이스트를 대체할 사워도우 제조 시 비타민나무 잎을 첨가하는 것은 바람직한 것으로 생각된다.

발효 팽창력은 반죽의 gluten 생성 능력 및 가스 보유력에 영향을 받으며, 팽창력이 높을수록 제빵 적성에 바람직한 현 상으로 평가된다(Yang 등, 2010). 반죽의 발효팽창력은 발효 시간이 길어질수록 증가하는 경향을 보였다. 비타민나무 잎 사워도우 반죽의 발효팽창력은 발효가 진행되는 120 분 동안 20 분 간격으로 부피를 측정하였는데, 발효 시간 20-60분에서 $30 \%$ 첨가군이 $10.67-17.83 \mathrm{~mL}$ 로 가장 높았다. 발효 시간 80 120 분에서는 대조군과 시료 첨가군 간의 차이가 없었다. Lee (2015)는 반죽의 $\mathrm{pH}$ 가 증가할수록 $\mathrm{CO}_{2}$ 의 발생량이 감소하여 빵의 부피가 감소한다고 보고하였다. 이에 본 연구에서는 대 조군의 $\mathrm{pH}$ 가 시료 첨가군보다 높아 $\mathrm{CO}_{2}$ 발생량의 감소가 발 효팽창력이 감소하는 데 영향을 미친 것으로 판단된다.

\section{모닝빵의 높이, 굽기손실률, 비용적 및 수분함량}

비타민나무 잎 배합비율에 따른 사워도우 첨가 모닝빵의 높이, 굽기손실률, 비용적 및 수분함량 측정 결과는 Table 2 와 같다. 모닝빵의 높이는 $10 \%$ 첨가군이 $4.62 \mathrm{~cm}$ 로 가장 컸 으며, $30 \%$ 첨가군이 $4.25 \mathrm{~cm}$ 로 가장 낮아 $10-30 \%$ 시료 첨가 에 따라 감소하는 경향을 보였다. 막걸리 사워도우(Yoo 등, 2017), 발아 카무트 분말(Yoon 등, 2020)을 첨가한 식빵의
연구에서도 시료 첨가량이 증가할수록 높이가 감소한다고 보 고하여 본 실험 결과와 유사한 경향을 보였다.

반죽은 굽는 과정에서 높은 열과 발효 중 생성된 휘발성 물질의 영향으로 팽창한다. 이때 반죽 내의 생성된 기공에 의 해 휘발성 물질과 수분이 함께 증발하면서 일정량의 굽기 손실 이 발생한다(Kim 등, 1978). 모닝방의 굽기손실률은 $30 \%$ 첨가 군이 $10.02 \%$ 로 가장 높게 나타났다. 홍국을 이용한 sourdough bread(Lee 등, 2007), 아로니아 sourdough starter를 이용한 모닝빵(Sim 등, 2019)의 연구에서는 시료 첨가량이 증가할수 록 굽기손실률이 증가한다고 보고하여 비타민나무 잎 $30 \%$ 의 배합비율은 이들 결과와 유사하게 모닝빵의 굽기손실률을 증 가시키는 것으로 생각된다. 또한 Fujiyama(1984)는 반죽의 굽기손실률은 일반적으로 7-13\% 발생한다고 보고하여 비타 민나무 잎 배합비율에 따른 사워도우 첨가 모닝빵의 굽기손 실률이 8.63-10.02\%로 일반적인 굽기손실률 범위에 포함되 어 있다는 것을 알 수 있었다.

모닝빵의 비용적은 대조군이 $4.04 \mathrm{~mL} / \mathrm{g}$ 으로 컸으며, 10 $30 \%$ 첨가군이 $3.62-3.81 \mathrm{~mL} / \mathrm{g}$ 으로 유의적인 차이를 보이지 않았다. 사워도우와 퀴노아 분말 첨가 모닝빵 연구(Jung 등, 2020)에서도 시료 첨가량이 증가할수록 비용적이 감소하는 것으로 나타났다. 이러한 결과는 빵 반죽의 글루텐 발달 저하 및 가스 보유력 감소로 발생하며, 글루텐의 희석이 영향을 미 친다고 보고하였다. 본 실험에서도 비타민나무 잎 배합비율 이 증가할수록 밀가루의 양이 감소하여 글루텐의 발달이 저 하되고, 가스 보유력의 감소로 모닝빵의 비용적이 감소한 것 으로 사료된다.

수분함량은 빵의 촉촉함, 부드러운 질감을 부여하고, 빵의 맛을 평가하는데 중요한 요소이다(Czuchajowska 등, 1989). 
Table 2. Height, baking loss rate, specific volume, and moisture content of morning bread added with sourdough starter according to the mixing ratio of sea buckthorn leaf

\begin{tabular}{ccccc}
\hline & Control $^{1)}$ & SBLS 10 & SBLS 20 & SBLS 30 \\
\hline Height (cm) & $4.40 \pm 0.16^{2) \mathrm{b} 3)}$ & $4.62 \pm 0.18^{\mathrm{a}}$ & $4.33 \pm 0.09^{\mathrm{bc}}$ & $4.25 \pm 0.13^{\mathrm{c}}$ \\
Baking loss rate (\%) & $9.01 \pm 0.21^{\mathrm{c}}$ & $9.42 \pm 0.28^{\mathrm{b}}$ & $8.63 \pm 0.40^{\mathrm{d}}$ & $10.02 \pm 0.28^{\mathrm{a}}$ \\
Specific volume ( $\mathrm{mL} / \mathrm{g})$ & $4.04 \pm 0.13^{\mathrm{a}}$ & $3.81 \pm 0.23^{\mathrm{b}}$ & $3.62 \pm 0.05^{\mathrm{b}}$ & $3.69 \pm 0.17^{\mathrm{b}}$ \\
Moisture content (\%) & $30.61 \pm 1.39^{\mathrm{ns} 4)}$ & $29.95 \pm 1.11$ & $30.53 \pm 1.03$ & $29.25 \pm 0.85$ \\
\hline
\end{tabular}

${ }^{1)}$ Control, sourdough starter without sea buckthorn leaf; SBLS 10, 10\% sea buckthorn leaf sourdough starter; SBLS 20, 20\% sea buckthorn leaf sourdough starter; SBLS 30, 30\% sea buckthorn leaf sourdough starter; SBLS, sea buckthorn leaf sourdough starter.

${ }^{2)}$ Result are mean values $\pm \mathrm{SD}(\mathrm{n}=5)$.

3)a-c Means with different letters in the same row are significantly different by Duncan's multiple range test at $\mathrm{p}<0.05$.

${ }^{4)} \mathrm{ns}$, not significant.

모닝빵의 수분함량은 대조군과 비타민나무 잎 사워도우 첨가 군 간의 차이가 없었다.

\section{모닝빵의 색도}

비타민나무 잎 배합비율에 따른 사워도우 첨가 모닝빵의 색 도 측정 결과는 Table 3 과 같다. 색은 빵의 외관을 평가할 때 매우 중요한 요소 중 하나로 색이 좋으면 먹음직스럽게 보일 뿐만 아니라, 풍미 또한 향상시킬 수 있다(Kim 등, 2011). 모닝 빵의 $\mathrm{L}$ 값은 대조군이 61.33 으로 가장 밝았고, $0-30 \%$ 첨가군이 41.34-46.14로 시료 첨가량이 증가할수록 어두워지는 경향을 보였다. $a$ 값은 대조군에 비해 시료 첨가군이 다소 높았고, $b$ 값 은 시료 첨가량이 증가할수록 증가하였다. Jung 등(2020)은 모 닝빵의 색도는 첨가하는 부재료의 색에 영향을 받는다고 보고하 였으며, 시료 첨가량이 증가할수록 $\mathrm{L}$ 값이 감소하고 $\mathrm{a}$ 값, $\mathrm{b}$ 값은 증가한다고 보고하여 본 실험 결과와 유사하였다. 본 실험에서 사용된 비타민나무 잎은 녹색으로 chlorophyll계 색소가 다량 함 유되어 있다(Park, 2020). 클로로필은 약산 또는 $60^{\circ} \mathrm{C}$ 이상의 열을 가하면 올리브그린색(pheophytin)이 형성되며, 계속해서 산을 가하면 갈색(pheophorbide)이 형성된다(No 등, 2016). 따 라서 사워도우 발효 중에 생성되는 유기산과 비타민나무 잎의 chlorophyllo 반응하여 올리브그린색의 pheophytin으로 변화
되어 색도에 영향을 미친 것으로 사료된다.

\section{모닝빵의 조직감}

비타민나무 잎 배합비율에 따른 사워도우 첨가 모닝빵의 조직감 측정 결과는 Table 4 와 같다. 경도는 $20 \%$ 첨가군이 $301.54 \mathrm{~g}$ 으로 가장 높았다. 앞선 비용적 측정 결과(Table 2) 에서 $20 \%$ 첨가군은 다른 시료에 비해 낮은 비용적을 나타냈 는데, 다른 시료들과 유의적인 차이를 보인 것은 아니나 다른 시료에 비해 모닝빵의 부피가 작아 상대적으로 단단한 질감 을 나타낸 것으로 사료된다. 블루베리 천연 발효액종을 첨가 한 우리밀 식빵의 연구(Choi, 2013)에서는 시료 첨가량이 증 가할수록 경도가 증가한다고 보고하여 본 실험 결과와 다른 경향을 보였다. 탄력성은 대조군-30\% 첨가군이 0.46-0.50으 로 차이가 없었으며, 응집성 또한 유의적인 차이를 보이지 않 았다. 씹힘성과 검성은 $20 \%$ 첨가군이 가장 높고, $10 \%$ 첨가 군이 가장 낮게 나타났다. Lee 등(2009)은 씹힘성과 검성이 경도와 관련이 있다고 보고하였는데, 본 실험에서도 씹힘성 과 검성은 경도의 경향과 유사하게 나타났다.

\section{모닝빵의 총페놀 및 총플라보노이드 함량}

비타민나무 잎 배합비율에 따른 사워도우 첨가 모닝빵의

Table 3. Color values of morning bread added with sourdough starter according to the mixing ratio of sea buckthorn leaf

\begin{tabular}{ccccc}
\hline & Control $^{1)}$ & SBLS 10 & SBLS 20 & SBLS 30 \\
\hline Hunter L & $61.33 \pm 1.93^{2) \mathrm{a} 3)}$ & $46.14 \pm 2.01^{\mathrm{b}}$ & $44.86 \pm 3.55^{\mathrm{b}}$ & $41.34 \pm 1.98^{\mathrm{c}}$ \\
Hunter a & $-0.68 \pm 0.28^{\mathrm{d}}$ & $1.77 \pm 0.27^{\mathrm{a}}$ & $0.94 \pm 0.39^{\mathrm{b}}$ & $0.59 \pm 0.39^{\mathrm{c}}$ \\
Hunter b & $14.75 \pm 0.78^{\mathrm{d}}$ & $20.85 \pm 0.49^{\mathrm{c}}$ & $28.55 \pm 1.61^{\mathrm{b}}$ & $30.52 \pm 1.26^{\mathrm{a}}$ \\
\hline
\end{tabular}

${ }^{1)}$ Control, sourdough starter without sea buckthorn leaf; SBLS 10, 10\% sea buckthorn leaf sourdough starter; SBLS 20, 20\% sea buckthorn leaf sourdough starter; SBLS 30, 30\% sea buckthorn leaf sourdough starter; SBLS, sea buckthorn leaf sourdough starter.

${ }^{2}$ Result are mean values $\pm \mathrm{SD}(\mathrm{n}=5)$.

${ }^{3) a-d}$ Means with different letters in the same row are significantly different by Duncan's multiple range test at $\mathrm{p}<0.05$. 
Table 4. TPA (texture profile analysis) of morning bread added with sourdough starter according to the mixing ratio of sea buckthom leaf

\begin{tabular}{ccccc}
\hline & Control $^{1)}$ & SBLS 10 & SBLS 20 & SBLS 30 \\
\hline Hardness (g) & $228.16 \pm 27.38^{2 \text { b3) }}$ & $174.63 \pm 39.90^{\mathrm{c}}$ & $301.54 \pm 54.91^{\mathrm{a}}$ & $250.38 \pm 54.51^{\mathrm{b}}$ \\
Springiness (\%) & $0.46 \pm 0.11^{\mathrm{ns} 4)}$ & $0.50 \pm 0.03$ & $0.47 \pm 0.03$ & $0.49 \pm 0.02$ \\
Cohesiveness (\%) & $0.45 \pm 0.08^{\mathrm{ns}}$ & $0.49 \pm 0.03$ & $0.44 \pm 0.03$ & $0.47 \pm 0.03$ \\
Chewiness (g) & $48.35 \pm 17.56^{\text {bc }}$ & $42.06 \pm 6.15^{\mathrm{c}}$ & $61.87 \pm 7.52^{\mathrm{a}}$ & $57.33 \pm 10.13^{\mathrm{ab}}$ \\
Gumminess (g) & $101.28 \pm 19.13^{\mathrm{bc}}$ & $84.48 \pm 15.87^{\mathrm{c}}$ & $131.01 \pm 18.30^{\mathrm{a}}$ & $116.74 \pm 21.03^{\mathrm{ab}}$ \\
\hline
\end{tabular}

${ }^{1)}$ Control, sourdough starter without sea buckthorn leaf; SBLS 10, 10\% sea buckthorn leaf sourdough starter; SBLS 20, 20\% sea buckthorn leaf sourdough starter; SBLS 30, 30\% sea buckthorn leaf sourdough starter; SBLS, sea buckthorn leaf sourdough starter.

${ }^{2}$ Result are mean values \pm SD $(n=10)$.

${ }^{3) a-c}$ Means with different letters in the same row are significantly different by Duncan's multiple range test at $\mathrm{p}<0.05$.

${ }^{4)} \mathrm{ns}$, not significant.

총페놀 및 총플라보노이드 함량 측정 결과는 Fig. 1과 같다. 모닝빵의 총페놀 함량은 대조군-30\% 첨가군이 $16.62-106.84$ $\mathrm{mg} \mathrm{GAE} / 100 \mathrm{~g}$ 으로 비타민나무 잎 배합비율이 증가할수록 유의적으로 증가하였다 $(\mathrm{p}<0.05) . \operatorname{Park}(2020)$ 은 비타민나무 잎의 총폴리페놀 함량이 $133.75 \mathrm{mg} \mathrm{GAE} / \mathrm{g}$ 으로 매우 높다고 보고하였다. 이에 비타민나무 잎 배합비율의 증가가 모닝빵 의 총페놀 함량 증가에 영향을 미친 것으로 사료된다.

모닝빵의 총플라보노이드 함량은 대조군-30\% 첨가군이 6.32-44.36 mg NE/100 g으로 대조군에 비해 $30 \%$ 첨가군이 약 7.02배 증가하여 가장 높은 함량을 나타냈다. 비타민나무 열매가루 첨가 식빵 연구(Lee와 Kim, 2020)에서 시료에 함 유된 catechin, rutin 및 quercetin 함량이 식빵의 총페놀 함량

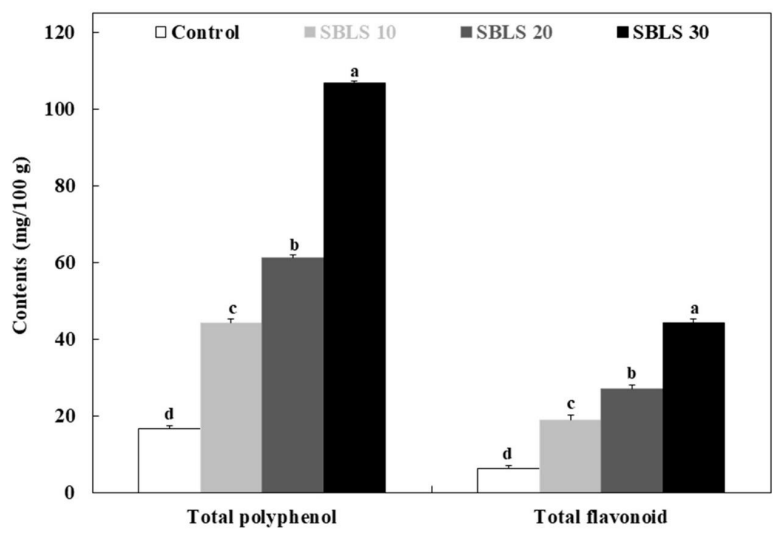

Fig. 1. Total polyphenol and total flavonoid contents of morning bread added with sourdough starter according to the mixing ratio of sea buckthorn leaf.

Control, sourdough starter without sea buckthorn leaf; SBLS 10, 10\% sea buckthorn leaf sourdough starter; SBLS 20, 20\% sea buckthorn leaf sourdough starter; SBLS 30, 30\% sea buckthorn leaf sourdough starter; SBLS, sea buckthorn leaf sourdough starter. GAE, gallic acid equivalent; NE, naringin equivalent.

a-c Means ( $n=3)$ with different letters are significantly different by Duncan's multiple range test at $\mathrm{p}<0.05$.
에 영향을 주어 시료 첨가량에 따라 식빵의 총페놀 함량이 증가했다고 보고하였다. 비타민나무 잎은 다양한 기능성 물 질을 함유하고 있다고 알려져 있는데, 주된 페놀 및 플라보노 이드 물질로 gallic acid, isorhamnetin, quercetin, kaempferol, catechin 및 myricetin 등이 보고되었다(Kim 등, 2010). 따라 서 모닝빵 제조 시 비타민나무 잎 배합비율을 증가하는 것은 모닝빵의 항산화 물질을 증가시켜 이에 대한 항산화 효능을 기대할 수 있을 것으로 생각된다.

\section{모닝빵의 DPPH 라디칼 소거능}

비타민나무 잎 배합비율에 따른 사워도우 첨가 모닝빵의 $\mathrm{DPPH}$ 라디칼 소거능 측정 결과는 Fig. 2와 같다. 대조군이

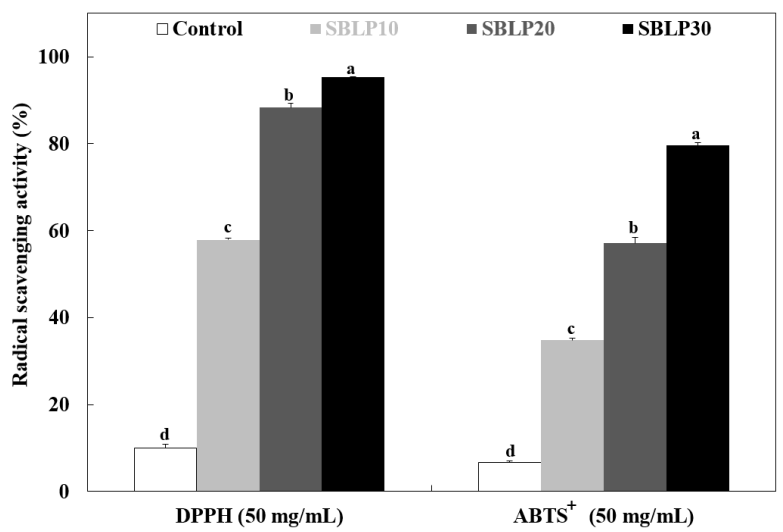

Fig. 2. DPPH and $\mathrm{ABTS}^{+}$radical scavenging activity of morning bread added with sourdough starter according to the mixing ratio of sea buckthorn leaf.

Control, sourdough starter without sea buckthorn leaf; SBLS 10, 10\% sea buckthorn leaf sourdough starter; SBLS 20, 20\% sea buckthorn leaf sourdough starter; SBLS 30, 30\% sea buckthorn leaf sourdough starter; SBLS, sea buckthorn leaf sourdough starter.

${ }^{a-d}$ Means $(n=3)$ with different letters are significantly different by Duncan's multiple range test at $\mathrm{p}<0.05$. 
$9.99 \%$ 로 DPPH 라디칼 소거능이 가장 낮았으며, 비타민나무 잎 사워도우 $10 \%, 20 \%, 30 \%$ 첨가군이 각각 $57.91 \%, 88.29 \%$, $95.24 \%$ 로 비타민나무 잎의 배합비율이 증가할수록 소거능이 최소 5.80 배에서 최대 9.53 배 증가하였다. 마른 김 첨가 모닝 빵(Baek 등, 2018), 아로니아 sourdough starter를 이용한 모 닝빵(Sim 등, 2019), 발아 카무트 분말 첨가 식빵(Yoon 등, 2020) 연구에서도 본 연구 결과와 유사하게 나타났는데, 이 러한 경향은 첨가되는 부재료의 항산화 물질이 DPPH 라디 칼 소거능에 영향을 주어 나타난 결과로 보고하였다. Lee 등 (2009)은 총페놀 함량 및 총플라보노이드 함량과 DPPH 라디 칼 소거능이 높은 양의 상관관계를 갖는다고 보고하였는데, 이는 본 실험에서 비타민나무 잎의 배합비율이 증가할수록 총페놀 및 총플라보노이드 함량이 증가하고, DPPH 라디칼 소거능도 증가한 결과와 일치하였다.

\section{모닝빵의 $\mathrm{ABTS}^{+}$라디칼 소거능}

비타민나무 잎 배합비율에 따른 사워도우 첨가 모닝빵의 $\mathrm{ABTS}^{+}$라디칼 소거능 측정 결과는 Fig. 2와 같다. 대조군이 $6.68 \%$ 로 소거능이 가장 낮았으며, 비타민나무 잎의 배합비 율이 증가할수록 소거능이 유의적으로 증가하였다 $(\mathrm{p}<0.05)$. 발아 카무트 분말(Yoon 등, 2020), 비타민나무 열매가루(Lee 와 Kim, 2020) 첨가 식빵 연구에서 시료 첨가량이 증가할수 록 식빵의 $\mathrm{ABTS}^{+}$라디칼 소거능이 증가한다고 보고하여 본 실험 결과와 유사하였다. 다만 본 실험에서 $\mathrm{ABTS}^{+}$라디칼 소거능이 DPPH 라디칼 소거능보다 낮게 나타났는데, 이는 $\mathrm{ABTS}$ (cation radical)과 $\mathrm{DPPH}$ (free radical)의 radical 차이에 의해 항산화 물질과 radical이 결합하여 제거하는 능력에 차 이가 발생하여 나타난 결과로 생각된다(Meir 등, 1995).

\section{모닝빵의 환원력}

환원력은 free radical 사슬이 reductone으로부터 제공되는 수소원자에 의하여 분해되면서 시작되며, 흡광도 수치가 곧 시료의 환원력을 뜻하는데, 환원력이 높은 물질이 많을수록 흡광도 값이 높게 측정된다(Jeong과 Shim, 2006). 비타민나 무 잎 배합비율에 따른 사워도우 첨가 모닝빵의 환원력 측정 결과는 Fig. 3 과 같다. 대조군이 0.61 O.D.으로 가장 낮았으 며, 비타민나무 잎 사워도우 $10 \%, 20 \%, 30 \%$ 첨가군이 각각 $1.23,1.86,2.38$ O.D.로 비타민나무 잎의 배합비율이 증가할 수록 환원력도 증가하였다. Lee와 $\operatorname{Kim}(2020)$ 은 비타민나무 열매가루를 첨가할수록 식빵의 환원력이 증가한다고 보고하 여 본 실험 결과와 유사한 경향을 보였다.

\section{관능적 품질}

비타민나무 잎 배합비율에 따른 사워도우 첨가 모닝빵의

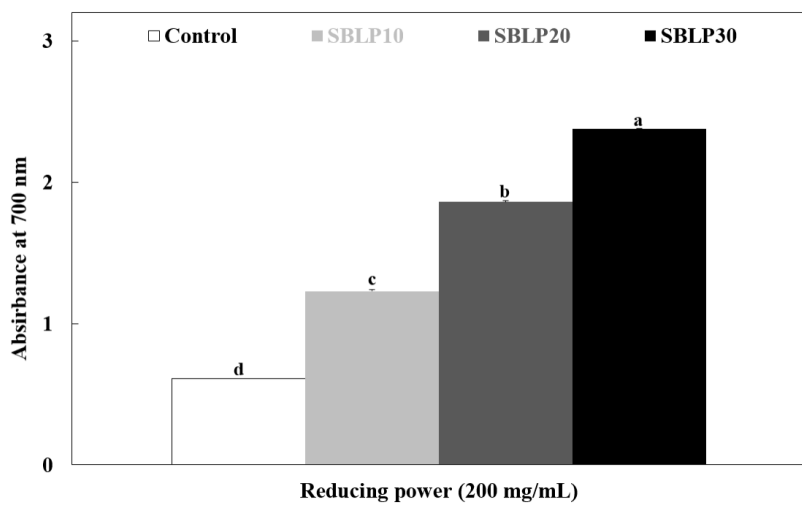

Fig. 3. Reducing power of morning bread added with sourdough starter according to the mixing ratio of sea buckthorn leaf.

Control, sourdough starter without sea buckthorn leaf; SBLS 10, 10\% sea buckthorn leaf sourdough starter; SBLS 20, 20\% sea buckthorn leaf sourdough starter; SBLS 30, 30\% sea buckthorn leaf sourdough starter; SBLS, sea buckthorn leaf sourdough starter.

${ }^{a-d}$ Means ( $\left.n=3\right)$ with different letters are significantly different by Duncan's multiple range test at $\mathrm{p}<0.05$.

관능검사 측정 결과는 Table 5 와 같다. 전반적인 기호도는 비 타민나무 잎 사워도우 $10 \%$ 와 $20 \%$ 첨가군이 각각 5.79 점, 6.07 점으로 높은 기호도를 보였고, $0 \%$ 첨가군이 5.71 점, $30 \%$ 첨가군이 4.93점 순이었다. 외관, 색, 향, 맛 및 조직감은 대조 군과 시료 첨가군 간의 유의적인 차이를 보이지 않았지만 모 두 보통(4점) 이상의 점수를 받았다. 막걸리 사워도우로 제조 한 식빵(Yoo 등, 2017)의 연구에서 사워도우를 첨가하면 전 반적인 기호도가 높아진다고 보고하여 본 실험 결과와 유사 한 경향을 보였다.

비타민나무 잎 배합비율에 따른 사워도우 첨가 모닝빵은 대조군과 비교해볼 때 외관, 색, 향, 맛 및 조직감에 차이가 없으며 전반적인 기호도는 높아지지만, $20 \%$ 이상 첨가할 경 우 오히려 기호도가 낮아지는 경향을 보였다. 따라서 품질 특 성, 항산화활성 및 관능적 기호도를 고려해볼 때, 비타민나무 잎 배합비율을 달리한 사워도우 첨가 모닝빵 제조 시 최적의 첨가량은 $20 \%$ 로 판단된다.

\section{요 약}

본 연구에서는 비타민나무 잎 분말을 이용하여 배합비율 $(0 \%, 10 \%, 20 \%, 30 \%)$ 을 달리한 사워도우를 제조한 후 모닝 빵 제조 시 첨가하여 품질 특성 및 항산화 활성을 측정하였다. 모닝빵 반죽의 $\mathrm{pH}$ 는 시료 첨가량에 따라 감소하였다. 발효팽 창력은 발효 시간이 길어질수록 모두 증가하였으며, 20-60분 에서는 $30 \%$ 첨가군이 가장 높았다. 모닝빵의 높이는 $30 \%$ 첨 가군에서 가장 낮았고, 굽기손실률은 $30 \%$ 첨가군이 가장 높 게 나타났다. 모닝빵의 비용적은 $0 \%$ 첨가군이 가장 컸으며, 
Table 5. Sensory scores of morning breads added with sourdough starter according to the mixing ratio of sea buckthom leaf

\begin{tabular}{cllll}
\hline & Control $^{1)}$ & SBLS 10 & SBLS 20 & SBLS 30 \\
\hline Overall preference & $5.71 \pm 1.14^{2) \mathrm{ab} 3)}$ & $5.79 \pm 1.05^{\mathrm{a}}$ & $6.07 \pm 0.73^{\mathrm{a}}$ & $4.93 \pm 1.27^{\mathrm{b}}$ \\
Appearance & $6.07 \pm 0.73^{\mathrm{ns} 4)}$ & $5.79 \pm 0.89$ & $5.64 \pm 1.01$ & $5.07 \pm 1.44$ \\
Color & $6.07 \pm 1.00^{\mathrm{ns}}$ & $5.79 \pm 0.80$ & $5.36 \pm 1.01$ & $5.14 \pm 1.46$ \\
Flavor & $5.21 \pm 0.97^{\mathrm{ns}}$ & $5.64 \pm 1.15$ & $5.79 \pm 1.89$ & $5.50 \pm 1.40$ \\
Taste & $5.29 \pm 1.14^{\mathrm{ns}}$ & $5.64 \pm 1.15$ & $5.79 \pm 0.89$ & $5.07 \pm 1.14$ \\
Texture & $4.71 \pm 1.27^{\mathrm{ns}}$ & $5.64 \pm 1.15$ & $5.50 \pm 0.94$ & $5.43 \pm 1.09$ \\
\hline
\end{tabular}

${ }^{1)}$ Control, sourdough starter without sea buckthorn leaf; SBLS 10, 10\% sea buckthorn leaf sourdough starter; SBLS 20, 20\% sea buckthorn leaf sourdough starter; SBLS 30, 30\% sea buckthorn leaf sourdough starter; SBLS, sea buckthorn leaf sourdough starter.

${ }^{2}$ Result are mean $\pm \mathrm{SD}(\mathrm{n}=15)$ using 7-point hedonic scale (1=extremely dislike, 4=normal, 7=extremely like).

${ }^{3) a-b}$ Means with different letters in the same row are significantly different by Duncan's multiple range test at $\mathrm{p}<0.05$.

${ }^{4)}$ ns, not significant.

$10-30 \%$ 첨가군은 유의적인 차이를 보이지 않았다. 모닝빵의 수분함량은 시료 간 차이가 없었으며, 색도는 시료 첨가량이 증가할수록 $\mathrm{L}$ 값은 감소하고 $\mathrm{b}$ 값은 증가하였다. 모닝빵의 경 도는 $20 \%$ 첨가군이 가장 높았고, 씹힘성과 검성은 경도와 유 사한 경향을 보였다. 모닝방의 총페놀 및 총플라보노이드 함량 은 사워도우 $30 \%$ 첨가군에서 가장 높았으며, $\mathrm{DPPH}, \mathrm{ABTS}^{+}$ 라디칼 소거능 및 환원력 또한 $30 \%$ 첨가군이 가장 높았다. 모닝빵의 관능검사 결과, 전반적인 기호도는 $20 \%$ 첨가군이 가장 좋았고 외관, 색, 향, 맛, 조직감은 시료 간 차이가 없었 다. 따라서 모닝빵 제조 시 이스트의 일부 대체로 비타민나무 잎 사워도우를 첨가하는 것은 모닝빵의 품질이 개선되고 항산 화 활성이 증가되므로 건강 기능성 빵으로써 개발이 바람직한 것으로 생각되며, 기호도 검사를 고려하여 비타민나무 잎의 배합비율은 $20 \%$ 가 가장 적절한 것으로 사료된다. 또한 사워 도우를 활용한 제빵산업의 기초자료로서 의미가 있으며, 향후 제빵산업 활성화에 기여함과 더불어 비타민나무 잎을 활용한 기능성 식품 개발의 연구로 가치가 있을 것으로 생각된다.

\section{Conflict of interests}

The authors declare no potential conflict of interest.

\section{ORCID}

Min Gyu Park https://orcid.org/0000-0003-4736-6715

Shin Youn Joo https://orcid.org/0000-0002-8009-1031

\section{References}

Angioloni A, Collar C. Nutritional and functional added value of oat, kamut ${ }^{\circledR}$, spelt, rye and buckwheat versus common wheat in breadmaking. J Sci Food Agr, 91, 1283-1292 (2011)

Baek SY, Kim SB, Kim MR. Antioxidant activities and physicochemical property of butter morning bread added with dried laver. J Korean Soc Food Sci Nutr, 47, 1242-1250 (2018)

Capelle S, Guylaine L, Gänzle M, Gobbetti M. History and social aspects of sourdough. In: Handbook of Sourdough Biotechnology, Gobbetti M, Ganzle MG (Editor), Springer, Heidelberg, Germany, p 1-17 (2013)

Choi SH. Quality characteristics of Korean wheat bread prepared with substitutions of naturally fermented blueberry starters. J East Asian Soc Diet Life, 23, 546-560 (2013)

Choi YH, Cho SS. Quality characteristics of Sulgidduk with different amount of dried Peucedanum japonicum powder. Culi Sci Hos Res, 24, 67-75 (2018)

Czuchajowska Z, Pomeranz Y, Jeffers HC. Water activity and moisture content of dough and bread. Cereal Chem, 66, 128-132 (1989)

Fujiyama Y. Baking Science \& Technology. Japan International Baking School, Tokyo, Japan, p 49-106 (1984)

Guan TT, Cenkowski S, Hydamaka A. Effect of drying on the nutraceutical quality of sea buckthorn (Hippophae rhamnoides L. ssp. sinensis) leaves. J Food Sci, 70, E514-E518 (2005)

Jeong $\mathrm{CH}$, Shim $\mathrm{KH}$. Chemical composition and antioxidative activities of Platycodon grandiflorum leaves and stems. J Korean Soc Food Sci Nutr, 35, 511-515 (2006) 
Jung JH, Han JH, Lee MH. Quality characteristics and antioxidant activity of morning bread with sourdough with quinoa powder. Culi Sci Hos Res, 26, 1-11 (2020)

Kallio H, Yang B, Peippo P. Effects of different origins and harvesting time on vitamin $\mathrm{C}$, tocopherols, and tocotrienols in sea buckthorn (Hippophae rhamnoides) berries. J Agric Food Chem, 50, 6136-6142 (2002)

Kim JS, Yu CY, Kim MJ. Phamalogical effect and component of sea buckthorn (Hippophae rhamnoides L.). J Plant Biotechnol, 37, 47-56 (2010)

Kim KM, Park MH, Kim KH, Im SH, Park YH, Kim YN. Analysis of chemical composition and in vitro anti-oxidant properties of extracts from sea buckthorn (Hippophae rhamnoides). Appl Biol Chem, 52, 58-64 (2009)

Kim MJ, Kim KBWR, Lee CJ, Kwak JH, Kim DH, Sun WC, Jung SA, Kang JY, Kim HJ, Choi JS, Choi HD, Ahn DH. Effect of Sargassum sagamianum extract on shelf-life and improved quality of morning bread. Korean J Food Sci Technol, 43, 723-728 (2011)

Kim MY, Chun SS. Changes in shelf-life, water activity, and texture of rye-wheat mixed bread with naturally fermented raisin extract and rye sourdough during storage. Korean J Food Cookery Sci, 25, 170-179 (2009)

Kim SK, Cheigh HS, Kwon TW, D'Appolonai BL, Marston PE. Rheological and baking studies of composite flour from wheat and naked barley. Korean J Food Sci Technol, 10, 11-15 (1978)

Kulp K, Lorenz K. Handbook of Dough Fermentations. Marcel Dekker Publishing, NY, USA, p 23-42 (2003)

Lee JH, Kwak EJ, Kim JS, Lee KS, Lee YS. A study on quality characteristics of sourdough breads with addition of red yeast rice. J Korean Soc Food Sci Nutr, 36, 785-793 (2007)

Lee JS, Kim JM. Quality characteristics and antioxidant properties of white pan bread added with sea buckthorn (Hippophae rhamnoids L.) berry powder. Korean J Food Nut, 33, 473-482 (2020)

Lee SH, Hwang IG, Nho JW, Chang YD, Lee CH, Woo KS, Jeong HS. Quality characteristics and antioxidant activity of Chrysanthemum indicum L., Chrysanthemum boreale M. and Chrysanthemum zawadskii K. powdered teas. J Korean Soc Food Sci Nutr, 38, 824-831 (2009)

Lee SH. Quality and antioxidant properties of white breads enhanced with broccoli (Brassica oleracea L.) powder.
Korean J Food Cookery Sci, 31, 614-622 (2015)

Lee SJ, Shin JH, Choi DJ, Kwen O. Quality characteristics of cookies prepared with fresh and steamed garlic powders. J Korean Soc Food Sci Nutr, 36, 1048-1054 (2007)

Lee SY, Jung HJ, Lee YE, Kim MR, Kim MR, Song HN. Food Chemistry. Powerbook, Goyang, Korea, p 279-402 (2009)

Lee SY, Shon JY, Kang KO. Nutritional components and antioxidant activities of sea buckthorn (Hippophae rhamnoides L.) leaf and berry extracts. J East Asian Soc Diet Life, 28, 31-39 (2018)

Lee YC, Hwang KH, Han DH, Kim SD. Compositions of Opuntia ficus-indica. Korean J Food Sci Technol, 29, 847-853 (1997)

Lee YK, Lee MY, Kim SD. Effect of calcium acetate on the dough fermentation and quality characteristics of bread. J East Asian Soc Diet Life, 13, 608-614 (2003)

Lin JY, Tang CY. Determination of total phenolic and flavonoid contents in selected fruits and vegetables, as well as their stimulatory effects on mouse splenocyte proliferation. Food Chem, 101, 140-147 (2007)

Meir S, Kanner J, Akiri B, Philosoph-Hadas S. Determination and involvement of aqueous reducing compounds in oxidative defense systems of various senescing leaves. J Agric Food Chem, 43, 1813-1819 (1995)

Moon HK, Han JH, Kim JH, Kim GY, Kang WW, Kim JK. Quality characteristics of bread with dried persimmons hot-water extracts. J Korean Soc Food Sci Nutr, 33, 723-729 (2004)

No JH, Yoon HN, Park SR, Yoo SJ, Shin MS. Color stability of chlorophyll in young barley leaf. J East Asian Soc Diet Life, 26, 314-324 (2016)

Pang X, Zhao J, Zhang W, Zhuang X, Wang J, Xu R, Xu $\mathrm{Z}, \mathrm{Qu}$ W. Antihypertensive effect of total flavones extracted from seed residues of Hippophae rhamnoides L. in sucrose-fed rats. J Ethnopharmacol, 117, 325-331 (2008)

Park MG. Studies on the antioxidant activities of sea buckthron leaf and its application to cookies. MS Thesis, Daejin University, Korea, p 59-64 (2020)

Park SY, Kim AJ, Han MR. Quality characteristics of oat bread with wild carrot (Daucus carota L.) powder. J Korean Soc Food Cult, 33, 55-61 (2018) 
Park YH, Lim SH, Ham HJ, Jeong HN, Lee KJ, Kim KH, Kim SM. Comparison of biological activities of extracts from different parts of sea buckthorn (Hippophae rhamnoides L.). J Korean Soc Food Sci Nutr, 39, 975-979 (2010)

Re R, Pellegrini N, Proteggente A, Pannala A, Yang M, Rice-Evans C. Antioxidant activity applying an improved ABTS radical cation decolorization assay. Free Radical Biol Med, 26, 1231-1237 (1999)

Sakandar HA, Hussain R, Kubow S, Sadiq FA, Huang W, Imran M. Sourdough bread: A contemporary cereal fermented product. J Food Process Pres, 43, e13883 (2019).

Sanz-Penella JM, Tamayo-Ramos JA, Haros M. Application of bifidobacteria as starter culture in whole wheat sourdough breadmaking. Food Bioprocess Tech, 5, 2370-2380 (2012)

Siepmann FB, Ripari V, Waszczynskyj N, Spier MR. Overview of sourdough technology: From production to marketing. Food Bioprocess Techn, 11, 242-270 (2018)
Sim S, Park YJ, Lee JH, Jeong SY, Lim JJ, Yu GH, Kim EG, Suh HJ. Quality characteristics and antioxidant activities of morning bread-containing aronia sourdough starter. J Food Hyg Saf, 34, 463-472 (2019)

Tae MH, Kim KH, Yook HS. Quality characteristics of bread with burdock (Arctium lappa L.) powder. J Korean Soc Food Sci Nutr, 44, 1826-1831 (2015)

Wong JY, Chye FY. Antioxidant properties of selected tropical wild edible mushrooms. J Food Compost Anal, 22, 269-277 (2009)

Yang SM, Shin JH, Kang MJ, Kim SH, Sung NJ. Quality characteristics of bread with added black garlic extract. Korean J Food Cookery Sci, 26, 503-510 (2010)

Yoo BS, Yun CS, Kim HA, Chang YH. Quality characteristics of white bread made with Makgeolli sourdough. Korean J Food Cook Sci, 33, 94-103 (2017)

Yoon JA, Han JW, Choi JH, Shin KO. Quality characteristics and antioxidant activity of white bread added with germinated kamut (Triticum turanicum Jakubz) Powder. J East Asian Soc Diet Life, 30, 345-354 (2020) 